\title{
Household-focused interventions to enhance the treatment and management of HIV in low- and middle-income countries: a scoping review
}

Ferdinand C. Mukumbang ${ }^{1 *}$ (D), Lucia Knight ${ }^{1}$, Caroline Masquillier ${ }^{2}$, Anton Delport ${ }^{1}$, Neo Sematlane ${ }^{1}$, Lorraine Tanyaradzwa Dube ${ }^{1}$, Martina Lembani ${ }^{1}$ and Edwin Wouters ${ }^{2}$

\begin{abstract}
Background: HIV remains a major public health challenge in many low- and middle-income countries (LMICs). The initiation of a greater number of people living with HIV (PLHIV) onto antiretroviral therapy (ART) following the World Health Organization's 'universal test and treat' recommendation has the potential to overstretch already challenged health systems in LMICs. While various mainstream and community-based care models have been implemented to improve the treatment outcomes of PLHIV, little effort has been made to harness the potential of the families or households of PLHIV to enhance their treatment outcomes. To this end, we sought to explore the characteristics and effectiveness of household-focused interventions in LMICs on the management of HIV as measured by levels of adherence, viral suppression and different dimensions of HIV competence. Additionally, we sought to explore the mechanisms of change to explain how the interventions achieved the expected outcomes.

Methods: We systematically reviewed the literature published from 2003 to 2018, obtained from six electronic databases. We thematically analysed the 11 selected articles guided by the population, intervention, comparison and outcome (PICO) framework. Following the generative causality logic, whereby mechanisms are postulated to mediate an intervention and the outcomes, we applied a mechanism-based inferential reasoning, retroduction, to identify the mechanisms underlying the interventions to understand how these interventions are expected to work.

Results: The identified HIV-related interventions with a household focus were multi-component and multidimensional, incorporating aspects of information sharing on HIV; improving communication; stimulating social support and promoting mental health. Most of the interventions sought to empower and stimulate self-efficacy while strengthening the perceived social support of the PLHIV. Studies reported a significant positive impact on improving various aspects of HIV competent household - positive effects on HIV knowledge, communication between household members, and improved mental health outcomes of youths living in HIV-affected households.

Conclusion: By aiming to strengthen the perceived social support and self-efficacy of PLHIV, householdfocused HIV interventions can address various aspects of household HIV competency. Nevertheless, the role of the household as an enabling resource to improve the outcomes of PLHIV remains largely untapped by public HIV programmes; more research on improving household HIV competency is therefore required.
\end{abstract}

Trial registration: PROSPERO registration: CRD42018094383.

Keywords: Households, Interventions, Family, HIV competency, Low-and middle-income countries

\footnotetext{
* Correspondence: mukumbang@gmail.com

'School of Public Health, University of the Western Cape, Cape Town, South

Africa

Full list of author information is available at the end of the article
}

(c) The Author(s). 2019 Open Access This article is distributed under the terms of the Creative Commons Attribution 4.0 International License (http://creativecommons.org/licenses/by/4.0/), which permits unrestricted use, distribution, and reproduction in any medium, provided you give appropriate credit to the original author(s) and the source, provide a link to the Creative Commons license, and indicate if changes were made. The Creative Commons Public Domain Dedication waiver (http://creativecommons.org/publicdomain/zero/1.0/) applies to the data made available in this article, unless otherwise stated. 


\section{Background}

There were an estimated 36.7 million people living with HIV (PLHIV) globally in 2017, with about 20.9 million accessing antiretroviral therapy (ART) [1]. Low- and middle-income countries (LMICs), especially in subSaharan Africa, are still the most affected by the HIV epidemic [2]. In 2014, UNAIDS launched the '90-90-90' goals to help end the HIV epidemic by 2030 through ensuring that by 2020, 90\% of PLHIV are diagnosed, $90 \%$ of those diagnosed are initiated on ART, and $90 \%$ of those on ART achieve viral suppression [3]. To encourage countries to achieve this goal, the World Health Organization (WHO) recommended the 'Universal Testand-Treat' (UTT) approach to increase the number of people who know their HIV status and initiate ART [4]. UTT is a strategy in which all individuals testing positive for HIV receive treatment irrespective of their CD4 count and clinical staging [5]. The UTT approach has encouraged LMICs to make impressive progress regarding the initiation of PLHIV on ART [6]. However, this significant increase in the number of PLHIV initiated on ART potentially places a greater burden on already vulnerable health systems such as in LMICs, especially in the context of limited human resources for health $[7,8]$.

Achieving the UNAIDS' goal depends significantly on retaining the increasing numbers of patients in care and by enhancing their adherence to ART [3]. Realising these objectives requires not only consistent access to ART but also continued psychosocial support and guidance of PLHIV [9]. Psychosocial support is predominantly provided by healthcare workers who are usually overburdened with other tasks [10]. To improve the psychosocial support of PLHIV in LMICs, various clientand community-level strategies have been designed [11], and delivered through task-shifting of ART care to other non-clinical staff [12] including the clients themselves [13]. While some of these strategies show provisional success, there is a need for more innovative and contextsensitive approaches [14].

Most psychosocial support interventions designed to improve medication adherence and retention in care in LMICs have been found to be individual- and/or community-focused, largely ignoring the crucial intermediate-level of the household [15-17]. In the context of limited human resources for health as is often the case in LMICs, families or households could thus potentially be a crucial resource to provide the psychosocial support required to adhere durably to ART. This is especially true in the context of UTT where increasing growing numbers of patients will start treatment [18]. To date, only a limited number of intervention studies have considered the household as a potential source of psychosocial support of PLHIV [19-21]. A scientific assessment of the existing evidence on the potential of families or households in HIV treatment adherence and retention is, therefore, a research priority.

In the field of social sciences, the idea of harnessing the strengths and capabilities of a household to provide psychosocial support to PLHIV is developed within the concept of an 'HIV competent household' [17, 22]. An HIV competent household is described as being an environment in which the patient can be supported across the HIV care continuum, from testing HIV positive to ensuring suppressive medication adherence, for long periods. Therefore, HIV competent households should be able to; (1) gain, share and translate HIV-related knowledge into prevention and treatment support behaviour; (2) create a safe space for disclosure and HIV dialogue; (3) foster HIV prevention practices and testing; (4) build solidarity to support self-management of the illness and (5) be receptive to outside support [17]. Within this context, there is a consensus that strengthening the capacity of households to enhance the treatment and care of PLHIV is one of the most important strategies to improve their health outcomes [23, 24]. Therefore, interventions targeting the households of PLHIV to stimulate HIV competence offers a promising opportunity to systemically address the clinical, intra, and interpersonal issues that may arise for PLHIV $[25,26]$.

The household has often been used as the context of care for PLHIV but not as the target for interventions [27]. While HIV household-focused prevention and management strategies are increasingly becoming a priority in LMICs, there is little systematic assessment of the nature of interventions designed to improve the HIV competency of the households of PLHIV. To this end, we sought to explore the characteristics and effectiveness of household-focused interventions in LMICs on the management of HIV as measured by levels of adherence, viral suppression and different dimensions of HIV competence. Furthermore, through the conceptual lens of HIV competency, we sought to explore the mechanisms of change (social and psychological drivers of behaviour change) to unearth how the interventions achieve the expected outcomes.

\section{Methods}

We conducted a scoping review with thematic analysis and reported our processes and findings following the 'Preferred Reporting Items for Systematic Reviews and Meta-Analyses' (PRISMA) Statement [28]. Our review was embedded in the five steps specified by Arksey and O'Malley [29] for conducting reviews: (1) framing questions for a review; (2) literature search; (3) assessing the quality of studies (4); summarising the evidence; and (5) interpreting the findings. 


\section{Step 1: framing questions for a review}

The review was designed to answer two research questions: (1) What is the impact of household-focused interventions on the management of HIV in the context of HIV competence in LIMCs? We adopted the Population, Intervention, Comparison and Outcome (PICO) framework (Table 1) to determine the eligibility of the review question; (2) What are the mechanisms involved in generating the outcomes of these household-focused interventions? Our goal with this question is to understand how and why household-focused interventions would (or would not) improve the HIV competency of the households of PLHIV.

\section{Step 2: literature search}

FCM and CM systematically searched six databases Web of Science, PubMed, Medline, Psych-ARTICLES, Academic Search Complete and Cumulative Index of Nursing and Allied Health (CINAHL) - to identify relevant studies that report on interventions targeting households/families with at least one HIV-positive member to enhance primarily the adherence to ART and retention in care behaviours of PLHIV in LIMCs. We developed a generic Boolean phrase "(Famil* OR household*) [AND] (intervention* [OR] program*) [AND] HIV" to search the identified databases. In April 2018, we searched in the title and abstract or abstract only some of the search engines did not allow for a search in title and abstract concurrently, so we selected the abstract option assuming that words in a title are most likely to appear in the abstract. There were no language

Table 1 The Population-Intervention-Comparison-Outcome approach to framing our research question

\begin{tabular}{ll}
\hline PICO & Definitions \\
\hline Population & People Living with HIV/AIDS and their households/families \\
Intervention & Household -centred/targeted interventions \\
Comparison & Not applicable \\
Outcome(s) & Primary outcomes: \\
& Adherence to treatment; retention in care \\
& Secondary outcomes: \\
Individual-level: & - Improved quality of life \\
- Enabled self-management & - Disclosure \\
- Improved perceived social support \\
Household-level: \\
- Improved HIV knowledge and prevention practices - safe \\
sex (condom use) \\
- Attitude towards HIV and treatment; stigma; \\
communication about HIV, disclosure \\
- Household functioning - household relationship, system \\
maintenance \\
• HIV testing, treatment support at household, ownership \\
of the disease \\
• Provide support to a household member living with HIV
\end{tabular}

restrictions in our search as our team is multilingual. Google translate was used to translate the titles and abstracts of languages that none of the team members was familiar with.

While formulating the Boolean phrase, 'family' and 'household' were considered interchangeable. Nevertheless, we have to note that these two terms are not conceptually the same [30-32]. The use of 'family' as applied in implementation research has been challenged by various authors citing the lack of clarity in terms of definition and conceptualisation. This is particularly so within the African context, where 'family' is fluid, complex and extends both geographically and by degrees of relationship than the household [33-38]. Considering that it is those closest to the PLHIV who are the most likely to provide the support they require, it is likely to be the people within physical proximity who are also commonly close blood relations and household members. This understanding is in line with the definition by Rudie (2005) in Niehof [39]: who defines a household as a "co-residential unit, usually family-based in some way, which takes care of resource management and primary needs of its members" (p. 490). In this article, we use the term 'household' as a coresidential unit, most probably family-based, targeted by HIV-related interventions. Therefore, the mention of household-focused interventions should be considered as encompassing any existing family unit.

The references obtained from each database search were imported into the $Z_{\text {Zotero }}{ }^{\circ}$ reference manager. The software was then prompted to organise the imported references alphabetically. Each author was allocated a range of alphabets to screen the titles and abstracts. For instance, the first author screened from A-D. When unsure of whether a title was appropriate, Zotero ${ }^{\oplus}$ offers the option to view the abstract, which provides the reviewer more information to inform selection. Authors were asked to highlight each title/abstract they were uncertain about. FCM and AD rescreened the highlighted titles and decided on their inclusion/exclusion. Articles that qualified for inclusion based on the title and abstract screening were downloaded and screened by four authors (FCM, AD, NS and LTD). After the full text screening was completed, all four authors met to discuss and finalise the list of articles selected for inclusion. Disagreements were resolved by a majority vote amongst the four authors and if split, CM provided the final decision.

\section{Inclusion criteria}

- Low- and Middle-Income Countries - based on the World Bank's 2018 classification [40]

- Household-focused

- HIV or AIDS focus of research

- Peer-reviewed articles 
- Articles published from 2003 to 2018

\section{Exclusion criteria}

- Exclusive focus on vulnerable or key populations (Lesbian, gay, bisexual, transgender, queer, intersex (LGBTQI) and men having sex with men (MSM), sex workers, substance abuse and refugees).

- Strictly facility-based interventions

- Systematic reviews

- Protocols

The PRISMA flowchart (Fig. 1) illustrates the article screening process to obtain the articles that qualified for inclusion.

\section{Step 3: Assessing the quality of studies}

The National Heart, Lung, and Blood Institute's (NIHNHLBI) Quality Assessment of Systematic Reviews and Meta-Analyses (a collection of different assessment tools based on different study designs) was used to rate the quality of the articles included in the review. Studies that adopted different research designs were assessed using the appropriate tools (Table 1) [41]. Two of the authors (AD and NS) appraised each article independently and then a third author (FCM) reviewed their judgement and reconciled their differences. The Quality Assessment tool was used to rate the quality of studies as good, fair or poor (Additional file 1). Following the NIH-NHLBI guidelines, a grade of $75 \%$ or more was considered a good evidence; a grade of 60 to $75 \%$ was considered fair evidence. Any score below $60 \%$ was considered poor evidence.

\section{Step 4: Summarising the evidence \\ Data extraction}

The data were extracted thematically. The extraction process was adopted to inform the thematic exploration of the types, nature and effects of the interventions designed to improve household competency of PLHIV. Extraction of data from the identified papers was done based on the following criteria: (1) Study citation and setting; (2) Intervention type; (3) Focus of intervention; (4) Study design; (5) Outcome measures; (6) Study quality; and (7) Detailed description of outcome. (Additional file 1). The studies from which the data are obtained are mostly interdisciplinary.

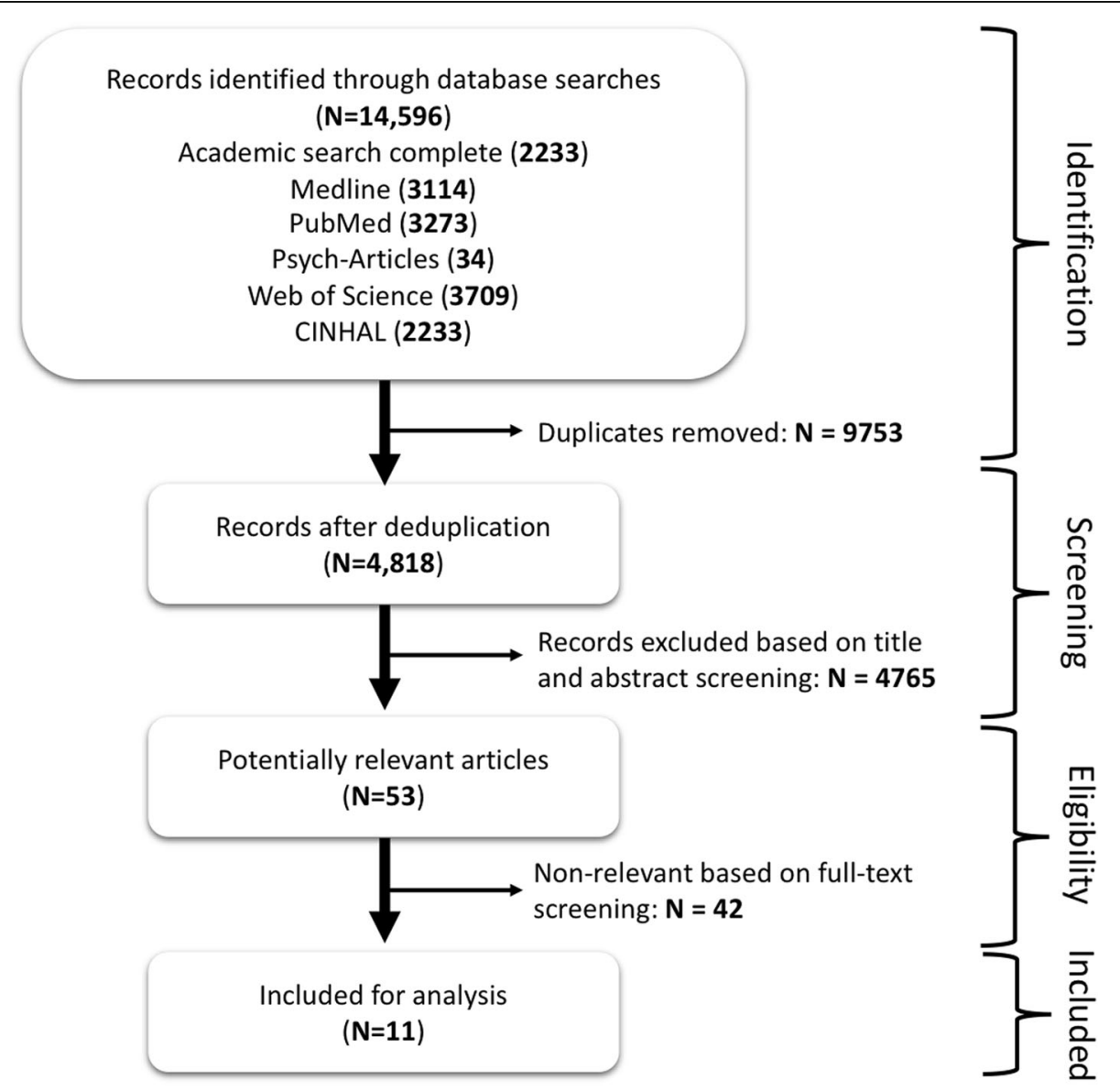

Fig. 1 PRISMA Flow Diagram 


\section{Data analysis}

Four of the authors (FCM, AD, NS, and ML) were involved in a discursive and iterative process to conduct the thematic grouping [42] and retroductive inferencing identifying and clarifying mechanisms theorised to have generated the outcome [43]. We used a thematic analysis approach to identify and classify the characteristics of the studies identified [44]. In addition, we classified the interventions described and evaluated in the identified studies into thematic groups using an aggregative or interpretive narrative synthesis method [44]. We used the HIV competency theoretical framework (Fig. 2) to explore the nature and characteristic of household-focused interventions to improve household HIV competency.

Our exploration of the mechanisms involved in generating the outcomes of household-focused HIV-related interventions followed the 'generative causality' framework. The generative causality framework, which suggests that a mechanism mediates the intervention and the outcome (Intervention $\rightarrow$ Mechanism $\rightarrow$ Outcome) [45] informed our identification of causal mechanisms. Identifying the generative mechanism(s) - the process of how subjects interpret and act upon (parts of) the intervention [24, 25] sheds light on how and why the intervention works or not. To unearth the underlying mechanism(s) of each intervention, we applied retroduction (mechanism-centred theorising). Retroduction warrants us to postulate, based on conceptual frameworks, models and theories described in the identified studies, the likely generative mechanism(s) that the intervention provides and/or activates [43]. To this end, we first explored the theory or theories that underpinned the design of each intervention.

\section{Results}

Results of the literature search

Table 2 shows the 14,596 identified references from various databases using various Boolean combinations.
The 14,596 search hits including articles in all languages were imported into the Zotero ${ }^{\circ}$ referencing software Versions 8.0. Using this software, we ran an electronic deduplication operation of the references identifying 9,489 duplicates. After the electronic deduplication, we hand-searched the remaining references and identified a further 289 duplicates: 9778 references were therefore removed through the deduplication process. The remaining 4818 references were eligible for the title and abstract screening.

Eleven articles were included for analysis (Fig. 1). The selection of studies for final inclusion was informed by the nature of the intervention (prevention vs treatment and management focused) and the location of the intervention implementation (facility, community vs homebased). Herein, we focused on proposed, piloted and implemented ART treatment and management interventions targeting the households either in part or entirely. Three of the interventions were rated as providing 'good' evidence, five as providing 'fair' evidence and the other three were unassessed as they described how the interventions were developed based on the NIH-NHLBI guidelines.

\section{Study characteristics}

Table 3 illustrates the characteristics of the 11 articles [46-56] obtained after the comprehensive and systematic search of the literature. We categorised these articles in relation to the type of evidence, the research approach adopted and the study design. These papers describe and/or evaluate nine interventions designed to improve aspects of support for households affected by HIV.

Eight of the designed interventions [46-49, 53-56] had been piloted and evaluated at a small scale while the other three articles [50-52] described the process of developing the intervention.

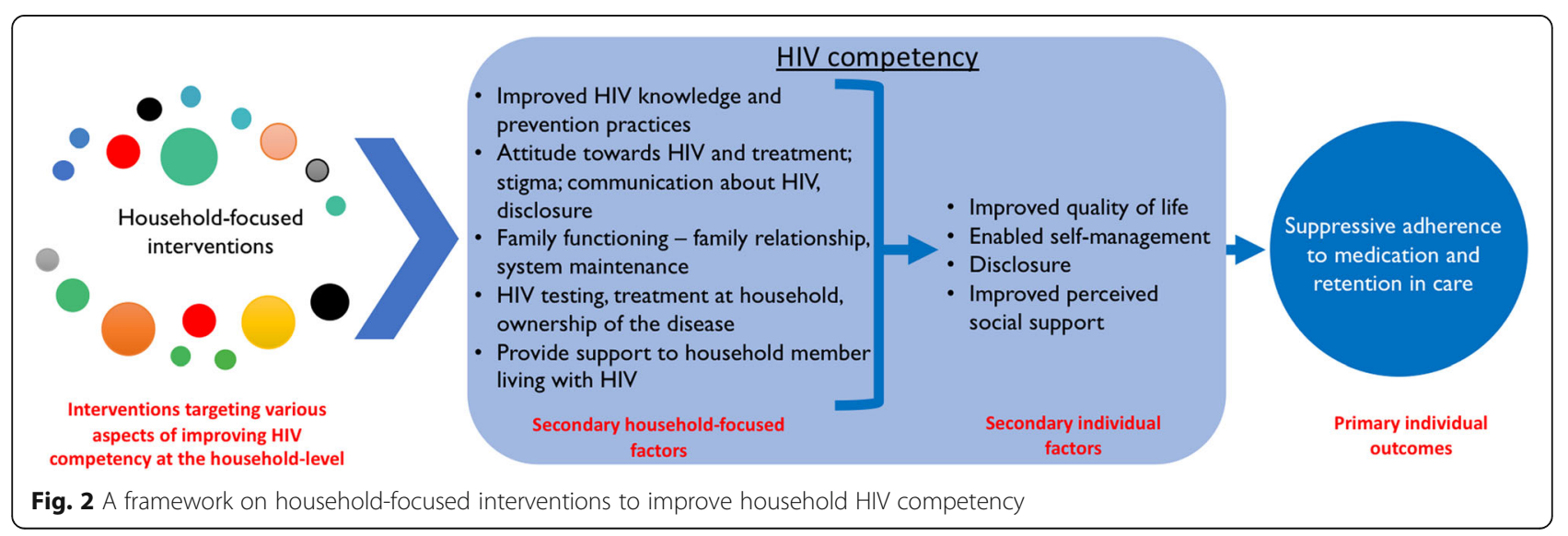


Table 2 The different databases searched, the Boolean combinations used and the number of hits identified

\begin{tabular}{|c|c|c|}
\hline Database & Boolean combinations applied & $\begin{array}{l}\text { References } \\
\text { identified }\end{array}$ \\
\hline PubMed & $\begin{array}{l}\text { (famil*[Title/Abstract] OR household*[Title/Abstract]) AND (program*[Title/Abstract] OR intervention*[itle/ } \\
\text { Abstract]) AND HIV*[itle/Abstract] }\end{array}$ & 3273 \\
\hline Web of Sciences & $\begin{array}{l}\left(\left(T S=\left(\text { Famil }{ }^{*}\right) \text { OR TS }=(\text { household } *)\right) \text { AND }(T S=(\text { program } *) \text { OR TS }=(\text { intervention } *)) \text { AND }\left(T S=\left(\text { HIV }^{*}\right)\right)\right) \text { AND } \\
\text { DOCUMENT TYPES: (Article) }-(\text { TS }=\text { topic }=\text { title }+ \text { abstract }+ \text { key words })\end{array}$ & 3709 \\
\hline $\begin{array}{l}\text { Academic search } \\
\text { complete }\end{array}$ & $(($ AB famil*) OR (AB household*)) AND ((AB intervention*) OR (AB program*)) AND (AB HIV) & 2233 \\
\hline Medline & ((AB famil*) OR (AB household*)) AND ((AB intervention*) OR (AB program*)) AND (AB HIV) & 3114 \\
\hline CINAHL & $(($ AB famil*) OR (AB household*)) AND ((AB intervention*) OR (AB program*)) AND (AB HIV) & 2233 \\
\hline Psych-ARTICLES & $(($ AB famil*) OR (AB household*)) AND ((AB intervention*) OR (AB program*)) AND (AB HIV) & 34 \\
\hline Total & & 14,596 \\
\hline
\end{tabular}

\section{Target population}

Eight of the 11 articles applied a dyadic principle to select the intervention participants. Five of the studies [48, $50,51,55,56]$ particularly focused on PLHIV younger than 18 years and their caregivers as the dyads. Four of the studies $[46,47,53,54]$ did not have age limitations for the PLHIV and enrolled any other household member aware of the HIV status of the PLHIV to complete the dyad. Two studies $[49,51]$ were individual-based interventions, focusing on the PLHIV in the household (Table 4).

\section{Interventions}

The 11 articles included in the review described nine different intervention packages targeting a household member living with HIV and another member who is either a caregiver of the person living with HIV or a dependent of the PLHIV.

Of the nine interventions identified, two were evaluations of existing programmes focused on providing information on HIV treatment adherence, counselling and

Table 3 Study characteristics by evidence type, the research approach adopted and the study design

\begin{tabular}{lll}
\hline Characteristics & $\mathrm{N}$ & References \\
\hline Evidence types & & \\
$\quad$ Evaluation research & 4 & {$[46][47][48][49]$} \\
Intervention development & 3 & {$[50][51][52]$} \\
Intervention development and evaluation & 4 & {$[53][54][55][56]$} \\
Research approaches & & \\
$\quad$ Quantitative methods & 4 & {$[46-49]$} \\
Qualitative methods & 3 & {$[50-52]$} \\
Mixed methods & 4 & {$[53-56]$} \\
Study designs & & \\
$\quad$ Cross-sectional & 3 & {$[53][54][48]$} \\
Formative research design & 4 & {$[56][50-52]$} \\
Randomised controlled trial & 4 & {$[55][46][47][49]$} \\
\hline
\end{tabular}

home-based care $[46,48]$. The other seven interventions $[46,47,50,51,53-55]$ were designed to improve aspects of support for families affected by HIV. Two papers, both reporting on the 'Family Strengthening Intervention' [53, 54], were focused on supporting parents by encouraging strong parenting skills through facilitated discussions. Another intervention, 'The Family Matters!' intervention, had similar goals to the 'Family Strengthening Interventions', and targeted 9-12 year-olds and their caregivers to promote positive parenting practices and effective parent-child communication about sexuality and sexual risk reduction [52]. Van Rooyen and colleagues [50] designed a study to assess the feasibility of expanding a home-based HIV counselling and testing model for adults to the whole family in a family-based counselling and testing intervention. Although the primary goal was to increase the uptake of HIV testing and linkage to care [50], the study also sought to improve family cohesion through addressing intergenerational communication challenges. Puffer et al. [56] in their study described a community-based intervention for family members from different households designed to strengthen family communication through modules on economic, relationship and HIV-related topics and improving the mental health of adolescents.

Table 4 A description of the populations targeted by the various interventions

\begin{tabular}{lll}
\hline Index person & Household member & Reference \\
\hline $\begin{array}{l}\text { Pre-adolescents } \\
\text { [9-12] }\end{array}$ & Caregiver & {$[51]$} \\
$\begin{array}{ll}\text { Adolescents } \\
\text { [10-16] [13-17] }\end{array}$ & Caregiver & {$[48][50]$} \\
$\begin{array}{l}\text { Pre-adolescents and } \\
\text { adolescents [7-17] }\end{array}$ & Caregiver & {$[55][56]$} \\
All ages & $\begin{array}{l}\text { Any household member } \\
\text { aware of the status of PLHIV }\end{array}$ & {$[46][54]$} \\
& N/A & {$[49][52]$} \\
$\begin{array}{l}\text { Undefined - No age } \\
\text { limitation }\end{array}$ & & \\
\hline
\end{tabular}


Other household-focused interventions were dedicated to promoting mental health among PLHIV and their affected household members. Li et al. [47, 49] described two multi-level family-focused interventions to improve the mental health (depressive symptoms) of both the PLHIV and their family members.

Five of the interventions used more than one approach to deliver different components of the intervention [4852]. For improving knowledge on various aspects of HIV and adherence, counselling through lay counsellors was the primary delivery approach $[46,48,50]$. To improve family functioning and cohesion, group discussions with the PLHIV and caregivers were predominantly used [47, 49, 51]. For caregivers of PLHIV, the researchers focused on providing knowledge that would empower the caregivers on how to support the PLHIV [52]. Three interventions were delivered in the form of a facilitated discussion among the PLHIV and their caregivers or had aspects of facilitated discussion as part of the delivery approach [47, 49, 51]. Table 5 further illustrates the other characteristics of the interventions and their frequencies in the identified studies.

Four of the interventions $[46,50,53,54]$ used trained Lay Counsellors or Community Healthcare Workers for delivery. In three studies $[47,52,55]$, health educators with formal bachelor's degree qualifications were used to deliver the interventions. One study indicated the use of a bachelor level counsellor [55], and another study used a certified facilitator (formal bachelor's degree qualification) to deliver their interventions [52]. The Puffer et al. [56] study used a community advisory committee to deliver the intervention. Nevertheless, the community advisory committee had people from different professional backgrounds, not particularly trained in delivering health care and health promotion related services.

Regarding the point of delivery of each intervention, nine of the interventions described reported that either part or the whole intervention was delivered within the home of PLHIV [46-48, 50, 51, 53-55]. Another four studies reported delivering at least parts of the intervention at a healthcare facility $[46,47,49,52]$. In most instances, the health care facility was the point of recruitment of the study participants and for obtaining baseline data from the study participants. Following the recruitment and baseline information, the designed intervention is delivered at the homes of the sampled participants. Four of the studies reported that parts of or all of their interventions were delivered out-of-clinic and out of PLHIV's household [47, 49, 52, 56]. The study conducted by Winskell et al. [52] had components of the intervention delivered at the facility and the other parts in the community. Some of the intervention aspects of the study conducted by Fatti et al. [46] were delivered at the local health facility and the other aspects were
Table 5 A description of the intervention modalities, mode of delivery, and characteristics

\begin{tabular}{|c|c|c|}
\hline Intervention characteristics & N & References \\
\hline \multicolumn{3}{|c|}{ Nature of intervention - how it was administered } \\
\hline $\begin{array}{l}\text { Teaching/education (information } \\
\text { sharing) }\end{array}$ & 3 & {$[56][50][52]$} \\
\hline Counselling & 3 & {$[46][48][50]$} \\
\hline Interactive activities & 6 & [53] [54] [49] [47] [51] [52] \\
\hline Facilitated discussions & 3 & {$[47][51][49]$} \\
\hline Interviews & 1 & {$[55]$} \\
\hline Home-based care & 1 & {$[48]$} \\
\hline \multicolumn{3}{|l|}{ Intervention Facilitator Qualification } \\
\hline $\begin{array}{l}\text { Lay Counsellor/Community Healthcare } \\
\text { Workers }\end{array}$ & 4 & {$[53][54][46][50]$} \\
\hline Community Advisory Committee & 1 & {$[56]$} \\
\hline Bachelor-level counsellor & 1 & {$[55]$} \\
\hline Health Educators & 2 & [47] [49] \\
\hline Certified Facilitator & 1 & {$[52]$} \\
\hline Mental health clinicians & 2 & [53] [54] \\
\hline \multicolumn{3}{|l|}{ Point of intervention delivery } \\
\hline Facility-based & 4 & [46] [47] [52] [49] \\
\hline $\begin{array}{l}\text { Community-based (out-of-clinic and } \\
\text { out-of-PLHIV's home) }\end{array}$ & 4 & [47] [56] [52] [49] \\
\hline Home-based & 9 & $\begin{array}{l}{[53][54][55][46][47][48]} \\
{[50][51][49]}\end{array}$ \\
\hline \multicolumn{3}{|l|}{ Components of intervention } \\
\hline Information/education on HIV/AIDS & 7 & {$[55][46][48][50-52,56]$} \\
\hline Adherence counselling & 3 & [46] [48] [52] \\
\hline Improving communication & 8 & $\begin{array}{l}\text { [53] [54] [55] [47] [50] [51] } \\
\text { [52] [49] }\end{array}$ \\
\hline Nutrition & 1 & {$[46]$} \\
\hline Disclosure & 3 & [46] [50] [52] \\
\hline $\begin{array}{l}\text { Identity, acceptance, resilience and } \\
\text { coping with HIV }\end{array}$ & 7 & $\begin{array}{l}{[53][54][55][47][51][52]} \\
{[49]}\end{array}$ \\
\hline Stigma and discrimination & 5 & [55] [46] [47] [52] [49] \\
\hline Sex education & 2 & {$[56][52]$} \\
\hline Social support & 7 & $\begin{array}{l}{[53][54][55][48][56][51]} \\
{[52]}\end{array}$ \\
\hline $\begin{array}{l}\text { Understanding the lived experiences' } \\
\text { of PLHIV }\end{array}$ & 2 & {$[55][52]$} \\
\hline Substance abuse & 1 & {$[46]$} \\
\hline Depressive symptoms & 3 & {$[46][47,49]$} \\
\hline Violence (intimate partner violence) & 1 & {$[46]$} \\
\hline Healthy living & 3 & {$[47-49]$} \\
\hline Economic empowerment & 1 & {$[56]$} \\
\hline HIV testing & 1 & {$[50]$} \\
\hline Risk-taking behaviour & 2 & {$[51,52]$} \\
\hline
\end{tabular}


delivered at the household of the study participants. Li et al. $[47,49]$ described the "Together for Empowerment Activities (TEA)" intervention that had different components delivered at the health care facility, community and household.

\section{Outcomes}

The outcomes reported below were obtained from the articles in which a formal analysis was conducted to investigate the impact of the intervention (eight interventions and articles). The other three articles only described the process of intervention development. The outcomes of the interventions were explored with regard to our primary outcomes (retention in care and adherence to medication) and secondary outcomes. The secondary outcomes were further dichotomised to individual and family-level outcomes (Table 6).

Our findings showed that only one study reported on our primary intended outcomes (Table 6) [46]. This study reported on the eight-year outcomes of adherence to medication, retention in care and the mortality rate of PLHIV receiving a home-based adherence and psychosocial support intervention. The study showed improved long-term ART outcomes among patients receiving an integrated community/home-based care intervention in South Africa. It also showed lower chances of being lost to follow-up (adjusted risk ratio; 0.74 [95\%CI: 0.66-
0.84; $P<.0001])$ compared to those not enrolled in the intervention. For those on ART, the risk of not achieving viral suppression was $11.4 \%$ for patients using the intervention, and $19.4 \%$ among patients in standard care (adjusted risk ratio $=0.47$ [95\% CI: 0.26-0.86; $P=.015])$ [46].

In the studies conducted by Betancourt et al. [53, 54] and Li et al. [49], mental health was the primary focus, as well as being the secondary focus of two other studies $[47,56]$. Whether considered a primary or secondary outcome, improvements in subjective measures of mental health were observed in four of the five studies [47, $49,53,54]$. The interventions reported in these articles showed statistical significance in reducing depressive symptoms and the occurrence of anxiety (Table 6). The Puffer et al. [56] study evaluating a familyand church-based intervention for adolescents living with HIV, did not find a significant impact of the intervention on mental health, likely due to the low endorsement of symptoms at baseline as they did not specifically target adolescents with mental health concerns [56].

Five articles $[48,49,53,54,56]$ reported on individuallevel outcomes such as improvements in the level of acceptance of one's HIV status, building resilience in the face of challenges such as stigma, coping with HIV infection and self-management of HIV. Another four studies

Table 6 Intervention outcomes that were significant or non-significant

\begin{tabular}{|c|c|c|c|c|c|c|c|c|}
\hline \multirow[t]{2}{*}{ Characteristics } & \multicolumn{8}{|c|}{ References } \\
\hline & [53] & [54] & {$[55]$} & [46] & [47] & [48] & [56] & [49] \\
\hline \multicolumn{9}{|l|}{ Primary outcomes } \\
\hline Retention in care & & & & $\checkmark$ & & & & \\
\hline Adherence to medication & & & & $\checkmark$ & & & & \\
\hline \multicolumn{9}{|l|}{ Secondary outcomes } \\
\hline \multicolumn{9}{|l|}{ Individual-level: } \\
\hline \multicolumn{9}{|l|}{ Improved quality of life } \\
\hline Enabled self-management & & $\checkmark$ & & & & $\checkmark$ & & $\checkmark$ \\
\hline Disclosure & & & & & & $\checkmark$ & & \\
\hline Improved perceived social support & & $\checkmark$ & & & $\checkmark$ & & $x$ & $\checkmark$ \\
\hline Improved mental health & $\checkmark$ & $\checkmark$ & $\checkmark$ & & $\checkmark$ & & $x$ & $\checkmark$ \\
\hline Risk behaviour (substance use, violence, sexual) & & & & & & & $\checkmark$ & \\
\hline \multicolumn{9}{|l|}{ Household-level (competency): } \\
\hline Household communication & & & & & & & $\checkmark$ & \\
\hline Improved HIV prevention practices - safe sex (condom use) & & & & & & & $\checkmark$ & \\
\hline \multicolumn{9}{|l|}{ Attitude towards HIV treatment } \\
\hline Ownership of the disease & & $\checkmark$ & & & & & & \\
\hline Household functioning & & $\checkmark$ & & & $\checkmark$ & & & \\
\hline Risk behaviour (substance use, violence, sexual) & & & & & & & & \\
\hline
\end{tabular}


[47, 53-55] reported significantly improved perceived social support by the PLHIV. Statistically significant results were also observed with improved quality of life [57] and reduced risky behaviour [56] - substance use, violence, sexual.

Regarding household outcomes, only one study included a component relevant to the disclosure of HIV status to household members. The relationships between the intervention and disclosure to household members was statistically significant, which means the intervention improved the rate at which PLHIV disclosed to other household members [48]. Chaudhury et al. [55] reported a statistically significant reduction in intimate partner violence among caregivers when they consumed less alcohol and their findings were supported by qualitative reports of improved family functioning. Family functioning - family relationship, system maintenance, and personal growth as a family/household outcome at the family/household-level - was discussed in two articles [47, 54]. Betancourt et al. [54] and Li et al. [47] found that the household-focused interventions they evaluated significantly improved family functioning. Li et al. [47] also found this relationship was significant for the PLHIV but they found no significant change in family function for the caregivers in a stratified analysis. Puffer et al. [56] did not assess the impact of the intervention on family functioning but did show improved communication within the household.

Other intervention outcomes for the family such as safe sex practices by other family members (caregiver) significantly improved in one of the studies [56]. Betancourt et al. [54] also reported a significant improvement in the ownership of and acceptance of the disease by the caregiver, this was indicated as improvements in caregiver-reported child perseverance/self-esteem.

\section{Mechanisms}

Interventions are theory incarnate [58], meaning that the design of any intervention carries with it an assumption of how and why the intervention is expected to work. It is postulated that for interventions to work, the interventions' participants must engage with the opportunities, resources and restraints that these interventions provide [58]. The reasoning, interpretation and actions that the actors adopt when exposed to the intervention modalities are assumed to cause the intervention outcomes [59]. Mechanisms of action, therefore, describe these causal forces, powers, processes or interactions that generate change within an intervention-including the choices, reasoning and decisions that people make as a result of the resources provided [59]. We focused on how the information and activities provided as part of the intervention influenced changes in the reasoning and actions of the participants [45] to explain how these interventions were expected to work.

While it was straightforward to identify the theory or theories that informed most of the interventions within the literature, some of the papers were adapted from previously designed parent studies, requiring review a of the original intervention study to identify the theory/theories. Interventions modified from the same parent interventions, therefore, had the same scaffolding theory such as the 'Together for Empowerment Activities' interventions $[47,49]$ and the "Family Strengthening Intervention" [39]. The different theories that underlie the development of the associated interventions and the mechanisms provided or activated by these interventions are indicated in Table 7.

Our analysis identified three primary mechanisms 'activated' by the interventions. A first mechanism identified speaks to empowering the PLHIV to disclose their HIV status and adopt health-enhancing behaviours. Empowerment as an essential generative mechanism refers to a sense of personal control, mastery, and power to effect change such as maintaining adherence to medication [60]. A second mechanism by which the intervention was proposed to work was improving the perceived social support of the PLHIV through improved interpersonal relationships. Perceived social support speaks to the feeling of being supported be it emotional, physical or practical support [60]. Improving perceived selfefficacy was the third identified mechanism by which these interventions were proposed to work. Self-efficacy refers to one's judgement of their ability and capabilities to carry out critical tasks towards achieving a particular goal. As Bandura [61] puts it, self-efficacy is the belief in one's ability to influence events that affect one's life and control over the way these events are experienced.

\section{Step 5: interpreting the findings Discussion}

Our study was designed to assess the impact of household-focused interventions on the management of HIV in the context of HIV competence in LMICs and to explore the mechanisms of change to explain how these interventions work. Our study found only nine interventions reported in 11 peer-reviewed articles addressing various aspects of the HIV competence of households affected by HIV. Our review findings are confirmed by similar observations made by Rotheram-Borus and colleagues [19] who noted the dearth of interventions designed to improve social support for PLHIV within the family in LMICs. Therefore, emphasis should be placed on the importance of strengthening households and family functioning with regard to HIV competency to support PLHIV [62]. 
Table 7 Identified interventions and possible intervention mechanisms

\begin{tabular}{|c|c|c|c|}
\hline Name of intervention & Theory of change & Possible mechanism & Reference \\
\hline Family Strengthening Intervention & Ecological Theory & Perceived social support & [53] \\
\hline Family Strengthening Intervention & Ecological Theory & Perceived social support & [54] \\
\hline Let's Talk & $\begin{array}{l}\text { Eco-development Theory } \\
\text { Cognitive Behavioural Theory }\end{array}$ & $\begin{array}{l}\text { Perceived social support } \\
\text { Improved self-efficacy }\end{array}$ & [51] \\
\hline The Families Matter! Programme & Social Learning Theory & Improved self-efficacy & [52] \\
\hline $\begin{array}{l}\text { Family-based prevention intervention to reduce alcohol } \\
\text { use and violence within HIV-affected families }\end{array}$ & Unidentified* & Unidentified* & [55] \\
\hline Community-Based Adherence Social Support & Unidentified* & Perceived social support & [46] \\
\hline Together for Empowerment Activities & Social Action Theory & Empowerment & [47] \\
\hline Integrated Community/ Home-based Care & Unidentified* & Perceived social support & [48] \\
\hline $\begin{array}{l}\text { Resilience, education, and Skills Development for Youth } \\
\text { and Families }\end{array}$ & Ecological Transactional Theory & $\begin{array}{l}\text { Improved self-efficacy } \\
\text { Perceived social support }\end{array}$ & [56] \\
\hline Integrated Family-Based counselling and Testing intervention & Ewart's social action theory & $\begin{array}{l}\text { Perceived social support } \\
\text { Improved self-efficacy }\end{array}$ & {$[50]$} \\
\hline Together for Empowerment Activities & Social Action Theory & Empowerment & [49] \\
\hline
\end{tabular}

Unidentified* No explicit theory associated with the intervention development was identified

Unnamed* No specific name was associated with the intervention

All the interventions identified in this review are multi-dimensional, addressing more than one aspect of psychosocial support. It is suggested by Simoni [63] that a comprehensive approach to designing behavioural interventions for the prevention and treatment of HIV has the potential of showing better success than single component interventions. The advantages of having a multidimensional intervention attending to structural barriers and individual-level determinants of HIV treatment vulnerabilities have been highlighted by various authors [64, 65]. Although the reviewed papers aimed to design and/ or evaluate the impact of household-focused interventions, none of these interventions captured all the five components of HIV competency as outlined by Masquillier et al. [17]. To this end, we recommend the design and implementation of interventions that would address the components of an HIV competent household.

We identified empowerment, perceived social support and self-efficacy as the prevailing mechanisms driving the way household-based interventions work. Our findings are corroborated by the Information-MotivationBehaviour (IMB) model, which suggests that a well-informed, well-motivated patient who possesses adequate skills for enacting complex patterns of adherencerelated behaviour will adhere to their ART regimen optimally over time [66]. Following the IMB model, household-focused interventions that provide information on how to support PLHIV can motivate PLHIV to adopt better health-seeking and medication adherence behaviours. Sharma and Sokhey [67] also found that various domains of self-efficacy like managing depression, managing fatigue, managing symptoms and getting support are positively correlated with physical functioning, cognitive functioning, mental health and QOL of PLHIV. To this end, improving the self-efficacy of PLHIV and their household members in their household environment can improve their health outcomes. Bhatta and Liabsuetrakul [68] recognised that empowerment is a key mechanism for addressing HIVrelated issues especially with regard to overcoming adverse conditions such as stigma and discrimination.

We argue that household-focused HIV interventions that seek to improve knowledge, attitudes and values; foster positive relationships; and increase communication can enhance social support and the overall functioning of the household to create a health-enabling environment [20]. Based on this evidence, therefore, living in a supportive conducive environment is appropriate for the PLHIV.

Some of the reviewed studies reported improved mental health outcomes (perceived stress, anxiety, and depressive symptoms), individual-level HIV competency (acceptance, resilience, coping, self-management) and improve perceived social support for the PLHIV in the household. Improved quality of life and reduced risky behaviour (substance use, violence, condomless sexual encounters) were also reported. Sikkema et al. [69] revealed that while community-based (including homebased) interventions seeking to improve problem-solving, skills training, and stress management are commonly used in LMIC, these interventions should remain attuned to issues that are unique to PLHIV such as improving the HIV competence of their households. The improved outcomes of PLHIV demonstrated by community-based and household interventions are confirmed by $\mathrm{Wu}$ and $\mathrm{Li}$ [70] who showed that there are benefits of delivering a 
comprehensive set of interventions to PLHIV, along with their household members, caregivers, and other members of the community.

Our review revealed that most of the interventions were delivered by trained lay counsellors and community health workers. The use of lower-level providers has been encouraged by many scholars and public health researchers [71-74]. This is in an effort to maximise the effective use of healthcare resources while ensuring the effective delivery of healthcare services [75]. Community health worker-led interventions appear to be effective and also cost-effective for certain health conditions, particularly when partnering with low-income, underserved, and racial and ethnic minority communities [76]. Sikkema et al. [69] identified the need for brief and scalable interventions that can be delivered by non-specialists while providing supervision. Some of our reviewed studies $[50,54]$ performed validity checks to ensure that the intervention could be successfully delivered by trained lay counsellors/community health workers and found the interventions could be effectively delivered by these healthcare worker cadres.

The review indicated that household-focused interventions are predominantly centred on providing information (on HIV and medication adherence) and relational components (communication and social support). Although the experience of living with HIV negatively impacts the overall functioning of the affected households [77], having a supportive environment provided by members of the household may improve the health outcomes and quality of life of PLHIV [57]. According to Winskell et al. [52], household centred approaches are able to address some of the broader contextual barriers to adherence and strengthen caregivers' knowledge and skills to offer the requisite support to PLHIV. Therefore, interventions designed to improve the HIV competence of households affected by HIV can be conceptualised as strength- or resilience-based interventions [78].

\section{Strengths and limitations}

The strength of this study lies on the fact that in addition to identifying and exploring the effects of various interventions implemented at the household-level to improve the HIV competency of the households of PLHIV, we also sought to identify the underlying programme theories informing their possible success. Particularly, we unearthed the possible mechanisms of action driving the uptake and success of these interventions.

Identifying the theory or theories that informed the development of the intervention was in some instances challenging. This also limited our ability to retroduce what possible mechanisms are in play in the intervention under consideration. To overcome this barrier, we traced the original article that reported on the design of the intervention. This process helped us to identify the proposed mechanism(s) of actions within each intervention. Following our article screening process, we observed that no large-scale studies were included, which could affect the inferences drawn on the effectiveness of the interventions under consideration.

The heterogenic nature of the studies included in the review did not allow for meta-analysis to be conducted to assess the overall impact of household-based HIV interventions to improve the household competency of the households of PLHIV. To this end, a scoping review with a narrative synthesis informed by thematic analysis became the possible option.

\section{Implications}

Our understanding of the types of household-based interventions to improve the household-competency for PLHIV has three implications. First, the study reveals the gaps concerning what aspect(s) of household competency is/are receiving more or less attention in the literature. Second, the scoping review indicates which interventions have shown success and which ones have not been very successful on improving various aspects of household competency. Third, this article unveils the programme theories, underlying the understanding of how and why these interventions were expected to work. These understandings can enhance the design and implementation of interventions to improve the experiences of PLHIV within their households regarding the self-management of their disease, which in turn improves ART adherence and retention in care.

Our review did not consider the feasibility or acceptability of the interventions designed to improve HIV household-competency. We suggest that assessing the feasibility and acceptability of HIV competent interventions should be considered to inform the scaling up and sustainability of these HIV competent interventions. This is particularly useful in the context of LMICs with weak health systems.

\section{Conclusion}

The importance of including other household members in the treatment and care of PLHIV has been long established. Notwithstanding, there remains a dearth of studies assessing the impact of household interventions on adherence and retention and household HIV competency. While a handful of interventions seek to improve the communication between PLHIV and their caregivers to enhance their disclosure, social support and reduce depressive symptoms, much still needs to be done to improve overall HIV household competency. To this end, more interventions designed to improve various aspects of the household HIV competency and consequentlly longterm retention and adherence to ART are needed. 


\section{Supplementary information}

Supplementary information accompanies this paper at https://doi.org/10. 1186/s12889-019-8020-6.

Additional file 1. Data extraction sheet. The extraction of relevant information from the 11 articles included in the review based on the characteristics of the intervention they report on and the study design adopted.

\section{Abbreviations}

ART: Antiretroviral therapy; CINAHL: Cumulative Index of Nursing and Allied Health; IMB: Information-Motivation-Behaviour; LGBTQI: Lesbian, gay, bisexual, transgender, queer, intersex; LMICs: Lower- and Middle-Income Countries; MSM: Men having sex with men; NIH-NHLBI: National Heart, Lung, and Blood Institute; PICO: Population, intervention, comparison and outcome; PLHIV: People living with HIV; QOL: Quality of life; SAT: Social Action Theory; TEA: Together for Empowerment Activities; UTT: 'Universal Test-and-Treat', WHO: World Health Organization

\section{Acknowledgements}

The authors thank Nina Sommerland for her guidance and support throughout the review process.

\section{Authors' contributions}

EW, LK, FCM and CM designed the scoping review. FCM and CM conducted the searches. FCM, AD, NS and ML analysed the data. FCM drafted the manuscript with editorial and content input from all the other authors. All authors read and approved the final manuscript.

\section{Funding}

This review is conducted with the support of Belgian Development Cooperation, through VLIR-UOS (Grant ZA2018TEA474A102), the Research Foundation - Flanders (FWO - G035018 N) and the South African Research Chairs Initiative of the Department of Science and Technology and National Research Foundation of South Africa (Grant No 98918).

\section{Availability of data and materials}

The dataset(s) supporting the conclusions of this article is (are) included within the article (and its additional file(s)).

\section{Ethics approval and consent to participate}

Not applicable.

\section{Consent for publication}

$\mathrm{N} / \mathrm{A}$

\section{Competing interests}

The authors declare that they have no competing interests.

\section{Author details}

${ }^{1}$ School of Public Health, University of the Western Cape, Cape Town, South Africa. ${ }^{2}$ Department of Social Sciences, Antwerp University, Antwerp, Belgium.

\section{Received: 9 May 2019 Accepted: 29 November 2019}

\section{0.}

\section{References}

1. UNAIDS. UNAIDS Data 2018. Retrieved from http://www.unaids.org/sites/ default/files/media_asset/unaids-data-2018_en.pdf.

2. Shao Y, Williamson C. The HIV-1 epidemic: low- to middle-income countries. Cold Spring Harb Perspect Med. 2012;2(3):a007187. https://doi.org/10.1101/ cshperspect.a007187.

3. Gupta A, Nadkarni G, Yang W-T, Chandrasekhar A, Gupte N, Bisson GP, et al. Early mortality in adults initiating antiretroviral therapy (ART) in low- and middle-income countries (LMIC): a systematic review and meta-analysis. PLoS One. 2011;6(12):e28691. https://doi.org/10.1371/journal.pone.0028691.

4. Hayes R, Sabapathy K, Fidler S. Universal testing and treatment as an HIV prevention strategy: research questions and methods. Curr HIV Res. 2011 Sep;9(6):429-45.
5. World Health Organization. Consolidated guidelines on the use of antiretroviral drugs for treating and preventing HIV infection 2016 recommendations for a Public Health approach [Internet]. Switzerland; 2016. Available from: http://apps.who.int/iris/bitstream/10665/208825/1/ 9789241549684_eng.pdf?ua=1.

6. Perriat D, Balzer L, Hayes R, Lockman S, Walsh F, Ayles H, et al. Comparative assessment of five trials of universal HIV testing and treatment in subSaharan Africa. J Int AIDS Soc. 2018;21(1). https://doi.org/10.1002/jia2.25048.

7. Kober K, Van Damme W. Scaling up access to antiretroviral treatment in southern Africa: Who will do the job? Lancet. 2004:364(9428):103-7.

8. Ac Hontelez J, Newell M-L, Bland RM, Munnelly K, Lessells RJ, Bärnighausen T. Human resources needs for universal access to antiretroviral therapy in South Africa: a time and motion study. Hum Resour Health; 2012; 10:39. doi: https://doi.org/10.1186/1478-4491-10-39.

9. Zongo M, Capochichi J, Gandaho P, Coppieters Y. Psychosocial care of people living with HIV in Benin. Sante Publique. 2009;21(6):631-9.

10. Mukumbang FC, Mwale JC, Van Wyk B. Conceptualising the factors affecting retention in Care of Patients on antiretroviral treatment in Kabwe District, Zambia, using the ecological framework. AIDS Res Treat. 2017;7356362. https://doi.org/10.1155/2017/7356362.

11. Kredo T, Ford N, Adeniyi FB, Garner P, Kredo T, Ford N, et al. Decentralising HIV treatment in lower- and middle-income countries. Cochrane Database Syst Rev. 2013;6:CD009987. https://doi.org/10.1002/14651858.

12. Callaghan M, Ford N, Schneider H. A systematic review of task-shifting for HIV treatment and care in Africa. Hum Resour Health. 2010;8:8. https://doi. org/10.1186/1478-4491-8-8

13. Mukumbang FC, Van Belle S, Marchal B, Van Wyk B. Realist evaluation of the antiretroviral treatment adherence club programme in selected primary healthcare facilities in the metropolitan area of Western Cape Province, South Africa: a study protocol. BMJ Open. 2016;6(4):e009977. https://doi. org/10.1136/bmjopen-2015-009977

14. Grimsrud $A$, Bygrave $H$, Doherty $M$, Ehrenkranz $P$, Ellman $T$, Ferris $R$, et al Reimagining HIV service delivery: the role of differentiated care from prevention to suppression. J Int AIDS Soc. 2016;19(1):21484. https://doi.org/ 10.7448/IAS.19.1.21484.

15. Wouters E, le Booysen F R, Masquillier C. Who Should We Target? The Impact of Individual and Family Characteristics on the Expressed Need for Community-Based Treatment Support in HIV Patients in South Africa. PLoS One. 2016;11:e0163963. https://doi.org/10.1371/journal.pone.0163963.

16. Masquillier C. Bridging the gap: the intermediate role of the household in community-based support for people living with HIV/AIDS in South Africa: Antwerp University; 2016; PhD thesis. Antwerp: Department of Sociology.

17. Masquillier C, Wouters E, Mortelmans D, van Wyk B, Hausler H, Van Damme W. HIV/AIDS competent households: interaction between a health-enabling environment and community-based treatment adherence support for people living with HIV/AIDS in South Africa. PLoS One. 2016;11(10): e0163963. https://doi.org/10.1371/journal.pone.0163963.

18. Larmarange J, Diallo MH, Mcgrath N, Iwuji C, Tanser F, Till B, et al. The impact of population dynamics on the population HIV care cascade : results from the ANRS 12249 Treatment as Prevention trial in rural KwaZulu-Natal (South Africa). J Int AIDS Soc. 2018;21(Suppl 4):e25128. https://doi.org/10. 1002/jia2.25128.

19. Rotheram-Borus MJ, Swendeman D, Lee S-J, Li L, Amani B, Nartey M. Interventions for families affected by HIV. Transl Behav Med. 2011;1:313-26.

20. Lightfoot M, Milburn N. Common elements of Family-based HIV interventions for adolescents. Couple Fam Psychol. 2012;2:120-33. https:// doi.org/10.1037/a0028832.

21. Bhana A, McKay MM, Mellins C, Petersen I. Bell C. J Int AIDS Soc International AIDS Society. 2010;13:1-8.

22. Masquillier C, Wouters E, Mortelmans D, van Wyk B. On the road to HIV/AIDS competence in the household: building a health-enabling environment for people living with HIV/AIDS. Int J Environ Res Public Health [Internet]. 2015;12: 3264-92 Available from: http://www.mdpi.com/1660-4601/12/3/3264.

23. Chandan $U$, Richter $L$. Strengthening families through early intervention in high HIV prevalence countries. AIDS Care. 2009;21(Suppl 1):76-82 [cited 2014 Feb 23] Available from: http://www.pubmedcentral.nih.gov/ articlerender.fcgi?artid=2903776\&tool=pmcentrez\&rendertype=abstract.

24. Rochat TJ, Bland R, Coovadia H, Stein A, Newell M-LL. Towards a familycentered approach to HIV treatment and care for HIV-exposed children, their mothers and their families in poorly resourced settings. Future Virol. 2011;6:687-96. 
25. Davey MP, Duncan TM, Foster J, Milton K. Keeping the family in focus at an HIV/AIDS pediatric clinic. Fam Syst Heal. 2008;26:350-5.

26. Tomlinson M. Family-centred HIV Interventions: lessons from the field of parental depression. J Int AIDS Soc. 2010;13(Suppl 2):S9 Available from: . [internet]. 2010/06/25 http://www.ncbi.nlm.nih.gov/pubmed/20573291.

27. Wacharasin C. Families suffering with HIV/AIDS: what Family nursing interventions are useful to promote healing? J Fam Nurs. 2010;16:302-21.

28. Moher D, Liberati A, Tetzlaff J, Altman DG, Group TP. Preferred Reporting Items for Systematic Reviews and Meta-Analyses: The PRISMA Statement. PLoS Med. Public Library of Science. 2009;6:e1000097.

29. Arksey H, O'Malley L. Scoping studies: towards a methodological framework. Int J Soc Res Methodol. 2005;8(1):19-32.

30. Sharma R. The Family and Family Structure Classification Redefined for the Current Times. J Fam Med Prim Care. Wolters Kluwer -- Medknow Publications. 2013;2:306-10.

31. Ball DW. The "Family" as a Sociological Problem: Conceptualization of the Taken-for-Granted as Prologue to Social Problems Analysis. Soc. Probl. Oxford University PressSociety for the Study of Social Problems. 1972;19: 295-307.

32. Bender DR. A refinement of the concept of household: families, coresidence, and domestic functions. Am. Anthropol. [internet]. Am Anthropol Assoc. 1967;69:493-504 Available from: http://links.jstor.org/sici?sici=0002-72 94(196710)2:69:5\%3C493:AROTCO\%3E2.0.CO;2-0.

33. Wittenberg M, Collinson MA. Household transitions in rural South Africa, 1996-2003. Scand J Public Health. 2007;35:130-7.

34. Makiwane M, Gumede NA, Makoae M, Vawda M. Family in a changing South Africa: structures, functions and the welfare of members. South Afr Rev Sociol. 2017:48:49-69.

35. Sooryamoorthy R, Makhoba M. The Family in modern South Africa: insights from recent research. J Comp Fam Stud. 2016;47:309-21.

36. Young L, Ansell N. Fluid Households, Complex Families: The Impacts of Children's Migration as a Response to HIV/AIDS in Southern Africa. Prof Geographer. 2003;55(4):464-76. https://doi.org/10.1111/0033-0124.5504005.

37. Heuveline P. Impact of the HIV epidemic on population and household structure: the dynamics and evidence to date. AIDS. 2004;18:S45-53 Available from: http://www.ncbi.nlm.nih.gov/entrez/query.fcgi?cmd= Retrieve\&db=PubMed\&dopt=Citation\&list_uids=15319743.

38. Yaw Amoateng A, Richter LM. Social and economic context of families and households in South Africa 1 chapter 2 chapter 4; 2007.

39. Niehof A. Conceptualizing the household as an object of study. Int J Consum Stud. 2011;35:488-97.

40. The World Bank. World Bank Country and Lending Groups - World Bank Data Help Desk. 2018. Retrieved from: https://datahelpdesk.worldbank.org/ knowledgebase/articles/906519-world-bank-country-and-lending-groups.

41. National Heart, Lung and BI. Study quality assessment tools | National Heart, lung, and Blood Institute (NHLBI) Retrieved from: https://www.nhlbi.nih.gov/ health-topics/study-quality-assessment-tools.

42. Miles M, Huberman M. Qualitative data analysis. Second Edi. California: Sage Publications, Inc: 1994.

43. Eastwood JG, Jalaludin BB, Kemp LA. Realist explanatory theory building method for social epidemiology: a protocol for a mixed method multilevel study of neighbourhood context and postnatal depression. Springerplus. 2014;3:12. https://doi.org/10.1186/2193-1801-3-12.

44. Snilstveit B, Oliver S, Vojtkova M. Narrative approaches to systematic review and synthesis of evidence for international development policy and practice. J Dev Effectiveness. 2012;4(3):409-29. https://doi.org/10.1080/ 19439342.2012.710641

45. Hedstrom P, Swedberg R. Social Mechanisms. Melbourne: Cambridge University Press; 1998. Retrieved from: http://people.soc.cornell.edu/ swedberg/1998 Social Mechanisms.pdf.

46. Fatti G, Mothibi E, Shaikh N, Grimwood A. Improved long-term antiretroviral treatment outcomes amongst patients receiving community-based adherence support in South Africa. AIDS Care. 2016;28(11):1365-72. https:// doi.org/10.1080/09540121.2016.1191605.

47. Li L, Ji G, Liang L-J, Ding Y, Tian J, Xiao Y. A multilevel intervention for HIV-affected families in China: together for empowerment activities (TEA). Soc Sci Med. 2011;73(8):1214-21. https://doi.org/10.1016/j. socscimed.2011.07.013.

48. Ncama BP. Acceptance and disclosure of HIV status through an integrated community/home-based care program in South Africa. Int Nurs Rev. 2007; 54:391-7.
49. Li L, Ji G, Liang L-J, Lin C, Hsieh J, Lan C-W, et al. Efficacy of a multilevel intervention on the mental health of people living with HIV and their family members in rural China. Health Psychol United States. 2017;36:863-71.

50. van Rooyen H, Essack Z, Rochat T, Wight D, Knight L, Bland R, et al. Taking HIV Testing to Families: Designing a Family-Based Intervention to Facilitate HIV Testing, Disclosure, and Intergenerational Communication. Front Public Heal. 2016;4:1-14 Available from: http://journal.frontiersin.org/article/10.33 89/fpubh.2016.00154.

51. Visser M, Thurman TR, Spyrelis A, Taylor TM, Nice JK, Finestone M. Development and formative evaluation of a family-centred adolescent HIV prevention programme in South Africa. Eval Program Plann England. 2018:68:124-34.

52. Winskell K, Miller KS, Allen KA, Obong'o CO. Guiding and supporting adolescents living with HIV in sub-Saharan Africa: The development of a curriculum for family and community members. Child Youth Serv Rev. 2016; 61:253-60.

53. Betancourt TS, Meyers-Ohki SE, Stevenson A, Ingabire C, Kanyanganzi F, Munyana $\mathrm{M}$, et al. Using mixed-methods research to adapt and evaluate a Family strengthening intervention in Rwanda. Afr J Trauma Stress. 2011 Jun; 2(1):32-45.

54. Betancourt TS, Ng LC, Kirk CM, Munyanah M, Mushashi C, Ingabire C, et al. Family-based prevention of mental health problems in children affected by HIV and AIDS: an open trial. AIDS. 2014;28(Suppl 3):S359-68. https://doi.org/ 10.1097/QAD.0000000000000336.

55. Chaudhury S, Brown FL, Kirk CM, Mukunzi S, Nyirandagijimana B, Mukandanga J, et al. Exploring the potential of a family-based prevention intervention to reduce alcohol use and violence within HIV-affected families in Rwanda. AIDS Care. 2016;28(Suppl 2):118-29. https://doi.org/10.1080/ 09540121.2016 .1176686

56. Puffer ES, Pian J, Sikkema KJ, Ogwang-Odhiambo RA, Broverman SA. Developing a Family-based Hiv prevention intervention in rural Kenya: challenges in conducting community-based participatory research. J Empir Res Hum Res Ethics. 2013:8:119-28.

57. Li L, Liang L-J, Lee S-J, lamsirithaworn S, Wan D, Rotheram-Borus MJ. Efficacy of an intervention for families living with HIV in Thailand: a randomized controlled trial. AIDS Behav. 2012;16:1276-85.

58. Pawson R, Sridharan S. Theory-driven evaluation of public health programmes. Evidence-based Public Heal. [Internet]. Oxford University Press; 2009 [cited 2017 Mar 13]. p. 43-62. Available from: http://www. oxfordscholarship.com/view/10.1093/acprof:oso/9780199563623.001.0001/ acprof-9780199563623-chapter-04 z.

59. Mukumbang FC, Van Belle S, Marchal B, Van Wyk B. An exploration of group-based HIV/AIDS treatment and care models in sub-Saharan Africa using a realist evaluation (intervention-context-actor-mechanism- outcome) heuristic tool: a systematic review. Implement Sci. 2017;12:107. https://doi. org/10.1186/s13012-017-0638-0.

60. Mukumbang FC, Van Belle S, Marchal B, van Wyk B. Exploring "generative mechanisms" of the antiretroviral adherence club intervention using the realist approach: a scoping review of research-based antiretroviral treatment adherence theories. BMC Public Health. 2017;17(1):385. https://doi.org/10. 1186/s12889-017-4322-8.

61. Bandura A. Perceived self-efficacy in cognitive development and functioning. Educ Psychol. 1993;28:17-148.

62. Richter LM, Sherr L, Adato M, Belsey M, Chandan U, Desmond C, et al. Strengthening families to support children affected by HIV and AIDS. AIDS Care [Internet]. Routledge; 2009 [cited 2014 Feb 20];21 Suppl 1:3-12. Available from: http://www.pubmedcentral.nih.gov/articlerender.fcgi?artid= 2903779\&tool=pmcentrez\&rendertype=abstract.

63. Simoni JM, Amico KR, Smith L, Nelson K. Antiretroviral adherence interventions: translating research findings to the real world clinic. Curr HIV/ AIDS Rep. 2010;7:44-51.

64. Collins LM, Kugler KC, Gwadz MV. Optimization of multicomponent behavioral and biobehavioral interventions for the prevention and treatment of HIV/AIDS. AIDS Behav. 2016;20:197-214.

65. Simoni JM, Amico KR, Pearson CR, Malow R. Strategies for promoting adherence to antiretroviral therapy: a review of the literature. Curr Infect Dis Rep. 2008;10(6):515-21.

66. Amico KR, Barta W, Konkle-Parker DJ, Fisher JD, Cornman DH, Shuper PA, et al. The information-motivation-behavioral skills model of ART adherence in a deep south HIV+ clinic sample. AIDS Behav. 2009;13:66-75. 
67. Sharma N, Sokhey G. Role of Coping Styles in Quality of Life of People Living with HIV/AIDS. Indian J. Heal Wellbeing. 2013;3(1):6.

68. Bhatta DN, Liabsuetrakul T. Social self-value intervention for empowerment of HIV infected people using antiretroviral treatment: a randomized controlled trial. BMC Infect Dis. 2016;16:272. https://doi.org/10.1186/ s12879-016-1634-8.

69. Sikkema KJ, Dennis AC, Watt MH, Choi KW, Yemeke TT, Joska JA. Improving mental health among people living with HIV: a review of intervention trials in low- and middle-income countries. Glob Ment Health. 2015;2:e19.

70. Wu L, Li X. Community-based HIV/AIDS interventions to promote psychosocial well-being among people living with HIV/AIDS: a literature review. Heal Psychol Behav Med. 2013;1:31-46. https://doi.org/10.1080/ 21642850.2013.822798

71. Lehmann U, Sanders D. Community health workers: what do we know about them? The state of the evidence on Programmes, Activities, Costs an Impact on Health Outcomes of Using Community Health Workers. Geneva: World Health Organization; 2007.

72. Moosa S, Derese A, Peersman W. Insights of health district managers on the implementation of primary health care outreach teams in Johannesburg, South Africa: a descriptive study with focus group discussions. Hum Resour Health. 2017;15(1):7. https://doi.org/10.1186/s12960-017-0183-6.

73. Tshuma N, Mosikare O, Yun JA, Alaba OA, Maheedhariah MS, Muloongo K, et al. Acceptability of community-based adherence clubs among health facility staff in South Africa: a qualitative study. Patient Prefer Adherence. 2017;11:1523-31. https://doi.org/10.2147/PPA.S116826.

74. Mwai GW, Mburu G, Torpey K, Frost P, Ford N, Seeley J. Role and outcomes of community health workers in HIV care in sub-Saharan Africa: a systematic review. J Int AIDS Soc. 2013;16:18586. https://doi.org/10.7448/IAS.16.1.18586.

75. Olaniran A, Smith H, Unkels R, Bar-Zeev S, van den Broek N. Who is a community health worker? - a systematic review of definitions. Glob Health Action. 2017;10(1):1272223. https://doi.org/10.1080/16549716.2017.1272223.

76. Kim K, Choi JS, Choi E, Nieman CL, Joo JH, Lin FR, et al. Effects of community-based health worker interventions to improve chronic disease management and care among vulnerable populations: a systematic review. Am J Public Health. 2016;106(4):e3-e28. https://doi. org/10.2105/AJPH.2015.302987.

77. Belsey MA. AIDS and the family: policy options for a crisis in family capital. Dep. Econ. Soc. Aff. New York: United Nations Department of Economic \& Social Development: UNAIDS; 2005.

78. Eustace RW. A discussion of HIV/AIDS family interventions: implications for family-focused nursing practice. J Adv Nurs. 2013;69(7):1660-72. https://doi. org/10.1111/jan.12006

\section{Publisher's Note}

Springer Nature remains neutral with regard to jurisdictional claims in published maps and institutional affiliations.

Ready to submit your research? Choose BMC and benefit from:

- fast, convenient online submission

- thorough peer review by experienced researchers in your field

- rapid publication on acceptance

- support for research data, including large and complex data types

- gold Open Access which fosters wider collaboration and increased citations

- maximum visibility for your research: over $100 \mathrm{M}$ website views per year

At $\mathrm{BMC}$, research is always in progress.

Learn more biomedcentral.com/submissions 